\title{
IDEO Product Development Case Analysis
}

\author{
Xiaoru Du \\ School of Design and Art, Wuhan Textile University, Wuhan, 430073, China
}

\begin{abstract}
IDEO is one of the successful product development companies, it established in 1991 and combined with 3 companies (David Kelley Design, ID Two and Matrix Product Design). As one of the world's leading design firms, IDEO won a large number of awards than other product development firms. This company has a rapidly development in last several years, owned over 660 employees in the various disciplines. IDEO help organizations in the public and private sectors to find new design approach to innovate and grow, its major well-know clients are include Apple Inc., AT\&T, Coca-Cola, Microsoft, Steelcase, PNC Financial Services and Palm. The company utilize design thinking as their main design process approach and focus on investigate and satisfied consumers' needs.
\end{abstract}

Keywords: IDEO Product Development; Design Process Approach; Management.

\section{Introduction}

In the recent years, with the development of society, the high technology driven people's life and change the world. Ahuja 2011 explained that high technology innovation is one of the extremely important factors for the majority of the companies to acquire success in the competitive society. Even though high technology innovation changed the world and advanced the standard of human lifestyle, it is not enough for the development of society. The society needs a new innovation method to satisfied individuals' needs, design thinking is new approach to reach that and become more and more important for society (Brown, 2009) Thus, there are a large number of the design companies appeared to the global market, these firms are focus on design and develop products and make them to satisfied consumers' needs. IDEO is one of the successful product development companies, it established in 1978 and rename to IDEO in 1991. To be more specific, in 1978, David Kelley established the David Kelley Design, because he found that the most of technological companies are lacking product development departments. After 13 years, David Kelley Design combines with ID Two and Matrix Product Design formed new product development firm in 1991 and renamed IDEO. As one of the world's leading design firms, IDEO won a large number of awards than other product development firms. This company has a rapidly development in last several years, owned over 660 employees in the various disciplines, such as behavior science, electrical engineering and design research et al. (IDEO 2015). As a product development firm, IDEO help organizations in the public and private sectors to find new design approach to innovate and grow. Sutton et al. (1996) reported that IDEO as a successful design company, they helped at least 40 industries to innovate and over 3000 products to development. This essay will be analyzed its process, organization, management and culture, to explore the reason of its success.

\section{Analysis of IDEO}

IDEO provides design services for clients from various areas, it coverage medical, computer, retail, food and automotive industries. The Apple's first mouse, the Palm V PDA and Steelcase's Leap chair are all product by IDEO its major clients are include Apple Inc., AT\&T, Coca-Cola, Microsoft, Steelcase, PNC Financial Services and Palm (IDEO, 2015). Nowadays, with the development the company, the IDEO are not only helps clients to develop the industrial products, they are involved in the various areas and accept the scope of the products. IDEO except help their clients to innovate and develop the industrial product, it also help client to design interactive experiences and build organization culture (IDEO, 2015). According to Rosenberg (1997) reported that IDEO's revenues reached 40-50 million dollars in 1996, and those revenues come from 90 percent in medical, consumer, 
telecommunications and 10 percent from industrial products. The reason of IDEO success is they put the consumer at the first place and use design thinking as approach to innovate. Tim Brown is president of IDEO, he addressed that design thinking is a human-centered approach to develop the products, and it is the extremely vital factor for product development firms to success (Brown, 2009). During the IDEO design process, they spend much time on investigating consumers' behavior and reveal consumers' potential needs.

\subsection{The Organization of IDEO}

The highly competitive business society led companies to acquire more opportunities and also bring the highly competitive pressure. Improving the competition in products' quality and cost, service and innovate new technology are not the only way to success, it is vital factor for companies seek out the new and suitable organization of companies to survive and success. The company's organization design is extremely important for them to survive and adapt to today's competitive business world (Galbraith, 2002). There are two major organization structures in the competitive business world, one of them is Hierarchical organization and another on is Flat organization. Hierarchical organization model, as a traditional organization structure model, are tend to adopt in large corporations, government and organized religions. It is likes a pyramid visual, they divided company's staff into different levels of management department. In contrast, Flat organization is devoted to reduce the middle managers and no level of management. This organization structure model has propounded by Hammer, Champy and Bryne in 1993 and implemented it into companies (Hernaus, 2008). Compare with Hierarchical organization, Flat organization make all the staff more productive and direct involved in the design process and enhanced the communication between company and client.

IDEO is an extremely successful example about company to adopt flat organization. Throughout IDEO company, it just has two levels of management and all of their projects are complete by the short time project team. There is no stable project team in IDEO, all the team are formed by different members and disbanded by the life of the project. Designers in IDEO are able to joint their interesting project, the leader of project team produced by person who has passionate and excited about project. There are some advantages of Flat organization structure in IDEO. Firstly when project team formed, the members of project team come from different disciplines. That will reduce the communication disorders during design process, making the project design more efficiently and effectively. Secondly, the lack of middle levels of management can avoided the competition of the designers and engineers in administrative position, it also led IDEO acquired a democracy workplace and employees are more productive. Finally, when the project team formed, they will communicate and make a decision with client directly. The less level of management can help the designers and engineers acquired the feedback of client with the rapidly speed it will led IDEO to develop the products more close to clients' needs and satisfied to consumers. IDEO success is not only because of innovate idea and products, the flat organization structure also contribute to its success. The lack of the levels of management help designers and engineers acquired consumers' information in the first time and help the company good at implementing their human-centered design approach.

\subsection{The Management of IDEO}

For the design company, how to manage designers and company's resources is very important. Even though there are lots of innovation ideas and advanced technology, companies still cannot survive in the competitive market without the maturity management methods. As a Flat organization structure company, IDEO is lack of lots of level of management and the hierarchy. The management of company became more important, the appropriate management and constraints can help IDEO more efficiently. Distinguished from other companies, IDEO woks are organized into small project team. Thus company addressed distributed management and self-management, they never implement core central enterprise management structure (Cicoria et al., 2013). A successful management model is built good communication with each one, IDEO is good at this field. All works are divided into the 
different project team in IDEO, manager produced in each project team. The leader of project is not a permanent position is like all of the team members, they elected by project team members and need joint whole design process. In this way, the communication barriers between manager and designers will get a significant decreased. Moreover, compare with other company often fired and punished employees, IDEO are good at manage and encourage their designers and engineers. The small project team stimulates employees' potential, each of members is unique and irreplaceable in the project team, all of them need to contribute for the project.

In addition IDEO built a flexible workplace and environment for employees, company encourage all the employees to design and decorate their studio with its own unique characteristics, employees tend to decorate the project team studio has its symbols and can represent their project team. For example, in one of IDEO Boston studio, the employees suspended a DC- 3 airplane wing from the ceiling as a symbol of their studio. That make the studio has become a place to work and play, and stimulate designers and engineers to innovate. Furthermore, in order to IDEO develop their flexible workplace and playroom atmosphere, "show and tells" activity will be held on Monday and engineers and designers can express their new ideas during this time. There is a "shoebox" in each of studio to motivate employees and inspired innovators, the box collects all kinds of interesting things. Its contains a wide range of new materials, devices and mechanisms exotic technology, IDEO designers often seek inspiration in these "shoebox". In conclusion, compere with the hierarchy companies, IDEO has more freedom and positive in their management. IDEO company tends to encouraging and motivate the enthusiasm of employees instead of punished and fired employees, the innovation management promote IDEO more efficiently and effectively.

\subsection{The Culture of IDEO}

Organizational culture is the key factor for companies and it is reflected in enterprise' central value, brief and principle of organizational members and workplace atmosphere. Human-centered is the key design principle of IDEO, company devote to solve client problem through consumers' perspective aspect. Throughout IDEO product development process, the prototyping is the central of their design philosophy. Using the product prototyping is a best way to understand client needs and seek out empathy with their end of users. For example, if IDEO help a company to design a telephone receiver, their just need a rough foam prototyping to find which shape is suitable for end users. IDEO encourage designers and engineers to create prototyping quickly and frequently, the designers and engineers in IDEO are did not care about the perfect looking about prototyping. Moreover, IDEO put Failure as their part of culture, they called it trail and error. Thomke et al. (2007) reported that IDEO encourage the employees to tried many times even though it failure, they consider that it likes straw man just experienced repeatedly knocked down then get success.

Additionally, all the employees in IDEO have strong teamwork awareness and the Collaborative Help is another part of culture in IDEO (Amabie et al., 2010). IDEO adopt the small unite team to finish the different project, helping became more important during their design process. Generally 4 or 5 employees form one project team, but those designers and engineers are come from all kinds of disciplines, such as: psychologists, scientists, engineers and marketing. When they faced the same question and problem, the various education background led them create vastly different solution. Company inspired the designers and engineers to produce a large number of ideas in the first stage, they the hope is from an absurd idea. Understand and help each other became essential part during the process, manager never rejected team members ideas and they often utilize the several sounds absurd ideas to develop and access the solution. Furthermore, IDEO also provide democracy and flexible work environment for employees. They did not require a dress code for employees and discourage the formal suit, company's management encourage employees communicate and interactions with each other. In IDEO's building, there are some unlocked loaner bicycles in order to help employee walk through each building. The management of IDEO tend to encourage employees to leave their workshop desk and walk around, that will inspired them more effectively during work. In otherwise, compare with other company, IDEO's offices are filled playroom atmosphere. All the 
IDEO project studio are designed by employees, team members often put studio suitable and stimulate them to innovate. Katz (1999) expressed when people walk into IDEO, they will feel energy and creative disarray fulfilled themselves. And in order to let all the project team members to express their own idea and insights, company required project team held brainstorming sessions frequently. No one will be able to disturb and reject others idea, designers and engineers owned a freedom place to dump your ideas. The flexible and playfulness workplace atmosphere will be better stimulate and motivate employees to innovate.

\subsection{The Process of IDEO}

The design process is the main factor for company to success, IDEO is good at product development process. During their product development process, IDEO project team will hold the frequently meeting with client and collect client feedbacks. That will make the product more satisfied by consumers' needs. The prototyping and brainstorming are the important approaches in product development process, Thomke et al. (2007) explained that prototyping and brainstorming are central to product development process, the prototyping is produced by their brainstorming sessions. The project team leader held daily brainstorm sessions during their design process, and less than 8 persons will be invited to attend this sessions. Perry (1995) claimed when individuals in the middle of the project and control the project details, then you will attend to brainstorm session and communicate your insights with others. The brainstorm sessions help project team to develop and close the solutions. In IDEO, employees should obey some principles about brainstorm sessions, such as: focus on the topic; inspire employees creating all kinds of ideas; never reject and interrupt others idea; based on other ideas to create and develop new idea; only permit one conversation and ensure every inviters get chance to express; produce a large number of ideas during this sessions; draw some visual image help other understanding your idea. Prototyping as the IDEO's design philosophy, it can help everyone imaging the same thing when they discuss. Company encourage rapid prototyping, they did not need a completed and perfect looking prototyping. Thus, good prototyping in IDEO followed by rough, rapid and right principles. IDEO encourage designers and engineers produce the prototyping with rapidly speed, they just need the prototyping focus on different small section of the project.

IDEO divided product development process into 5 steps, such as Understand / Observe, Visualize/ Realize, Evaluating/Refining, Implement /Detailed Engineering and Implement / Manufacturing Liaison (Thomke, 2007).

Phase 0: Understand / Observe

In this stage, project team will investigate the feasibility of product and understand the information of client business. When the project team undertakes this project, they will research all the aspect and history about clients and product. Compare with the secondary statistical data, IDEO project team are prefer to get primary data from their end users. By the end of the phases, the project team member can get specific information about the product then they will post the statistics and data on the project wall.

Phase 1: Visualize / Realize

In the phase 1 stage, IDEO project team will hold a large number brainstorm sessions and create numerous ideas, after that project team member will choose one aspect to develop complete idea based on the wildly ideas. During this stage, IDEO project team invited the client to attend the meetings frequently and get a rough prototyping.

Phase 2: Evaluating / Refining

In this stage, IDEO project team devoted to improve the prototyping and solve several functional problems, then get a final specific prototyping. During this process, IDEO project team members will produce many rough prototyping to practice and communication with clients or end users, then acquire their opinions to develop the prototyping. By the end of the phase, a final prototyping will be created and delivery to engineer sector. 
Phase 3: Implement / Detailed Engineering

In this stage, IDEO project team will finished the product design and testing. This is the final time to ensure and validate the functional final product. During this phase, the engineering dominate the product development. At the end, the project team completes the finally functional design model and starts to find vendors.

Phase4: Implement / Manufacturing Liaison

During the final phase, IDEO project team finished their all design problems about product. However, they still attend the product manufacturing process and ensure the product launches successful.

\section{Conclusion}

To sum up, IDEO as one of the world leading product development company, it owned many successful experiences and outstanding management approaches. This essay through IDEO's process, organization, culture and management to analyze IDEO company. In the fist part, it pointed that IDEO is an extremely successful company to adopt flat organization, and to analyze how IDEO through flat organization make employees more productively. Then it explained the IDEO distributed management and self-management approaches company tends to encouraging and motivate the enthusiasm of employees instead of punished and fired the employees After that this essay through enterprise' central value, brief and principle of organizational members and workplace atmosphere express IDEO culture. In the final part it characterize IDEO process, and divided the process into Understand / Observe, Visualize / Realize, Evaluating /Refining, Implement/Detailed Engineering and Implement / Manufacturing Liaison phases. IDEO as a successful product development company, it has a rapidly in the recent years and owned a large number well-know clients. However, it still exist some disadvantage in their company. With stronger of company, IDEO employed more staff and the flat organization bring some problems. It led project leader undertake huge responsibilities and difficult to constraint team members, because team member come from different sector and when the project finish they will disband. In order to pursue long-term development, IDEO need find a new approach to solve those problems.

\section{References}

[1] Amabile, T., Fisher, C.M. and Pillemer, J. (2010) IDEO's culture of helping. Harvard Business Review. [online] Available from: http://www.ds.ideo.tv/images/uploads/news/pdfs/R1401C-PDF-ENG_IDEO s_ Culture_of_Helping.pdf [Accessed 02/03/2015].

[2] Ahuja, I.P.S. (2011) Managing research and development for core competence building in an organization. Journal of Technology Management \& Innovation, 6(1), 58-65.

[3] Brown, T. (2009) Change by Design: How Design Thinking Transforms Organizations and Inspires Innovation. New York: HarperCollins.

[4] Cicoria, S., Sherlock, J., Clarke, L. and Muniswamaiah, M. (2013) IDEO and design thinking as an agile innovation practice. [Online] Available from: http:// www. cicoria. org/ papers/ IDEO $\% 20 \mathrm{and} \% 20$ Design\%20Thinking\%20as\%20an\%20Agile\%20Innovation\%20Practice.pdf [Accessed 05/03/2015].

[5] Galbraith, J. R., Lawler, E. et al. (1993) Organizing for the future. San Francisco: Jossey-Bass Publishers.

[6] Hernaus, T. (2008) Process-based organization design model: theoretical review and model conceptualization. Economics and Business. 1-17.

[7] IDEO. (2015) About IDEO. [Online] Available from: http://www.ideo.com/about/ [Accessed 02/03/2015].

[8] IDEO. (2015) Fact sheet. [Online] Available from: http:// www. ideo. com/ images/ uploads/ home/ IDEO_Fact_Sheet.pdf [Accessed 02/03/2015].

[9] Katz, B. (1999) A leadership style. Perspective.

[10] Perry, T.S. (1995) Design a culture for creativity. Research Technology Management, 38(2), 14-17.

[11] Rosenberg, R. (1997) By design, these firms take on other companies' products. The Boston Globe. 
[12] Sutton, R.I. and Hargadon, A. (1996) Brainstorming groups in context: effectiveness in a product design firm. Administrative Science Quarterly, Vol. 41, No. 4 (Dec., 1996), pp. 685-718.

[13] Thomke, S. and Nimgade, M.D. (2007) IDEO product development. Harvard Business School. [online] Available from: https:// scholar. google. co. uk/ citations? User=3ChhG88AAAAJ\&hl= zh-CN\&oi=sra [Accessed 02/03/2015]. 